\title{
Health Behaviors and Psychological Distress Among Conscripts of the Lithuanian Military Service: A Nationally Representative Cross-Sectional Study
}

\author{
Brigita Mieziene ${ }^{1, *}$, Arunas Emeljanovas ${ }^{1}$, Vida Janina Cesnaitiene ${ }^{1}$, Daiva Vizbaraite ${ }^{1}$ and \\ Renata Zumbakyte-Sermuksniene ${ }^{2}$ (D) \\ 1 Lithuanian Sports University, 44221 Kaunas, Lithuania; arunas.emeljanovas@lsu.lt (A.E.); \\ vida.cesnaitiene@lsu.lt (V.J.C.); daiva.vizbaraite@lsu.lt (D.V.) \\ 2 Lithuanian University of Health Sciences, 44307 Kaunas, Lithuania; renukz@gmail.com \\ * Correspondence: brigita.mieziene@lsu.lt; Tel.: +370-6868-4622
}

Received: 11 December 2019; Accepted: 23 January 2020; Published: 27 January 2020

\begin{abstract}
The decline in healthy behavior in young people is a concern for public health in general and for country's defense. The aim of this study is to identify and compare health behaviors and psychological distress between male conscripts enlisted and rejected for military service. This cross-sectional study included 1243 men aged 19-26 years (mean age $22.50 \pm 2.43$ years). We assessed health behaviors (physical activity, adherence to healthy eating patterns, cigarette smoking, and alcohol consumption) and psychological distress. Among all conscripts, $44.7 \%$ were physically inactive, $50.2 \%$ had low adherence to healthy nutrition, $9.6 \%$ were heavy drinkers, $62.3 \%$ were current smokers, and $9.1 \%$ had high psychological distress level. Compared with physically inactive conscripts, physically active conscripts were more likely to be enlisted (adjusted odds ratio $(\mathrm{OR})=1.42 ; 95 \%$ confidence interval $(\mathrm{CI}) 1.11-2.03)$. Compared with current nonsmokers, current smokers were less likely to be enlisted $(\mathrm{OR}=0.58$; $\mathrm{CI} 0.39-0.86)$. Compared with conscripts with a high distress level, those with a low distress level were almost four times more likely to be enlisted $(\mathrm{OR}=0.26$; 95\% CI 0.12-0.55). Adherence to guidelines for healthy eating and alcohol consumption was not significantly related to enlistment. These findings suggest that health behaviors in male conscripts are unsatisfactory. That is, about half are physically inactive, have a poor diet, and smoke, and nearly one in 10 is a heavy drinker and has a high psychological distress level. The enlisted conscripts were more likely to be sufficiently physically active and less likely to be a current smoker or have a high distress level. Early intervention programs to provide a heathier population of young men for conscription should focus on mental well-being and target health-related behaviors such as physical activity and not smoking. Preferably, these should be implemented as health education programs in schools to help prevent the development of adverse health behaviors among young men. Governmental policies and strategies are required to enable intersectional collaboration and shared responsibility among the education, military and health sectors.
\end{abstract}

Keywords: conscripts; physical activity; nutrition; smoking; alcohol consumption

\section{Introduction}

The decline in youth's healthy behaviors and related consequences [1] is of concern for public health in general and for national defense in particular, which requires a sufficient number of physically fit and mentally healthy military personnel. In Lithuania, there is evidence that young people do not partake in adequate physical activity; that is, only around $30 \%$ of students aged 18 years comply with the recommendation to be active $\geq 1 \mathrm{~h}$ on at least 5 days a week [2]. The trends for health-related 
physical fitness among adolescents have deteriorated in the past 20 years, and the indicators of cardiorespiratory fitness have decreased by nearly $50 \%$ during this period [3]. Only $13-14 \%$ of high school students comply with recommendations for healthy nutrition [4,5], $11 \%$ of young people consume alcohol [6]. Moreover, 22\% experience psychological distress [7]. Multiple health behaviors, psychological distress, and their associated risk factors, such as obesity and poor physical fitness, are associated with poor mental health outcomes, the risk of cardiovascular disease, type 2 diabetes, certain types of cancer [8,9], depression [10,11], and anxiety [12]. Unhealthy behaviors also impose an economic burden; for example, one study estimated that physical inactivity alone costs USD 53.8 billion in 2013 for healthcare worldwide [13].

Health is the main criterion for accepting or rejecting young men into military service (MS) and is strongly related to the ability to perform military duties. Unsatisfactory results of youth recruitment to Lithuanian MS have been presented: on average, 58.6\% of Lithuanian young men proceed through the full procedure of military enlistment. Among those who do not pass these procedures, 33\%-37\% experience psychological problems, $29 \%-33 \%$ have cardiovascular diseases, and $13 \%$ have musculoskeletal problems [14]. Other countries face similar problems of rejection from MS. For instance, analysis of the reasons for rejection from MS in the USA found that about $22 \%$ of rejections were because of problems with bones or joints, flat feet, or hernias, $15 \%$ because of organ defects, $13 \%$ because of defects of the cardiovascular system, $12 \%$ because of nervous system or mental problems, and $10 \%$ because of communicable diseases [15]. In the USA, Hispanic men appear to have a better health profile than their white and black peers, except for the prevalence of overweight, which is higher in Hispanic men [16].

Although health behaviors alone are not criteria for enlistment into MS, they might explain the reasons for some instances of rejection. Given that some health behaviors are risk factors for the occurrence of many lifestyle-related diseases [17], it is critical to identify whether and how health behaviors differ between young men who are deemed eligible and those who are ineligible for MS and to take appropriate actions to prevent adverse health behaviors from their onset.

Soldiers must be both physically and mentally healthy. However, mental health issues are among the main factors for rejection from MS [14,15]. Identifying psychological distress along with health behaviors might help to provide a more complete understanding of health indicators in conscripts as psychological distress is an indicator of mental health [18].

Given the associations between many health-related behaviors, the complex analysis of a set of risk behaviors instead of evaluation of individual associations may help to reduce the risk of missing potential confounders for enlistment into MS [19].

Several studies have examined psychological distress, health behaviors [20,21], and changes in health behavior [22] during MS. Enlistment is based on a medical examination of draftees, which may reject unhealthy individuals. As a result, these studies have evaluated health behaviors in relatively healthy youth but have not examined whether health behavior is related to the rejection of military recruits.

The aim of this study is to identify and compare health behaviors and psychological distress between male conscripts rejected for and enlisted into MS. We expect to find that healthier behaviors and low distress level would be related to a higher rate of enlistment into MS.

\section{Materials and Methods}

\subsection{Study Design and Procedure}

This nationally representative cross-sectional study was performed among Lithuanian conscripts. In Lithuania, 9-month-long MS is compulsory. In accordance with the conscription procedure of the Lithuanian Armed Forces, a list of potential draftees is created by an automatic electronic selection system each year and includes male Lithuanian citizens of compulsory MS-eligible age (19-26 years). Other male and female young adults can express their wish to be conscripted on a priority basis. 
A stratified random sampling was used. There are four centers for military recruitment in Lithuania that recruit conscripts during the whole year. The data were gathered in all four centers for 4 months from June to October 2018. Each conscript in these centers was approached during this period and asked to sign a consent form to participate in the study and to complete the study questionnaire. There was an equal chance (probability) that participants included in the study would be enlisted or rejected for MS.

The decision to accept a recruit for enlistment into MS is made by medical experts and is based on an individual medical examination and previous medical reports. The criteria for rejection from MS are defined in Order V-1142/V-1139, which provides a list of disorders along with their severity, and is signed by the Ministers of State Defense and Health Care. These criteria also indicate the minimum height requirement: 160 and $155 \mathrm{~cm}$ for men and women, respectively. Obesity without comorbid illness is not a reason for rejection from MS [23]. Enlistment in and rejection from MS were identified from the medical records for each study participant.

\subsection{Participants}

In 2018, there was a list of 10,340 conscripts, 209 of them female. This study included 1427 conscripts (which represented $13.80 \%$ of the total population), of whom 1296 returned their completed questionnaire along with their consent to participate in the study. The response rate was $90.82 \%$. Female recruits were invited to participate in the study, but because only 53 agreed to participate, they were later excluded because of the small sample size. Finally, 1243 young male potential conscripts were included in the analysis. The participants were aged 19-26 years and their mean age was $22.50 \pm 2.43$ years.

The Ministry of National Defense of the Republic of Lithuania approved the research. Ethics approval (No SMTEK-28, 2018) was obtained from the Ethics Committee of Lithuanian Sports University. The investigations were carried out following the rules of the Declaration of Helsinki of 1975, revised in 2013. Participants were informed of the tasks in the study before data collection, and all participants gave their informed consent for inclusion before they participated in the study.

\subsection{Measurements}

\subsubsection{Physical Activity}

The World Health Organization (WHO) defines moderate physical activity as activity that noticeably accelerates the heart rate and includes activities equivalent in intensity to brisk walking or bicycling. Vigorous physical activity causes rapid breathing and substantially increases heart rate, and includes activities such as jogging, aerobic dance, and bicycling uphill [24]. To assess physical activity in the participants in this study, we used the 2005 US Department of Defense Survey of Health Related Behaviors Among Active Duty Military Personnel [21]. The study participants were asked, "During the past 7 days, for leisure-time physical activity, how often did you usually do each of the following?". Participants were also asked, "During the past 7 days, when you did leisure-time physical activity, how long did you usually do each of the following?" For both questions, detailed descriptions and examples of what constitutes moderate and vigorous physical activity were presented.

In this study, we assessed physical activity during the preceding 7 days instead of the 30 days in the original questionnaire. Also, instead of using categorical answers (such as " 5 or 6 days" and "at least 20 minutes") for each question, we provided the opportunity to write the exact numbers of days, hours, and/or minutes per day. The number of minutes spent in was totaled. Participants whose MVPA was $<2.5 \mathrm{~h} /$ week were coded as not meeting health-related physical activity requirements and those whose MVPA was $\geq 2.5 \mathrm{~h} /$ week were coded as meeting health-related physical activity requirements [25]. 


\subsubsection{Eating Patterns}

A healthy eating pattern was defined as a diet based on whole or minimally processed foods and that included health-protective ingredients and lacked unhealthy items such as fast food and sugar-sweetened beverages [26]. Adherence to a healthy eating pattern was evaluated using the Mediterranean Diet Adherence Screener (MEDAS) [25], which was previously validated in Spanish and German adult populations [26,27]. The MEDAS includes 14 items: two indicate food-intake habits such as the use of olive oil and preference for white versus red meat, and the other 12 items capture the frequency of consumption of olive oil, animal fat, vegetables and fruits, fish, nuts, commercial pastries, sugar-sweetened beverages, and dishes with homemade sauce. Each item was scored as 0 (does not meet the healthy eating criteria) or 1 (meets the healthy eating criteria). The total score was calculated by summing all item scores. The MEDAS score was classified into three categories: $\leq 7$ indicated low adherence, 8-9 indicated medium adherence, and $\geq 10$ indicated high adherence to the Mediterranean $\operatorname{diet}[26]$.

\subsubsection{Alcohol Consumption}

Alcohol consumption was evaluated according to the 2008 US Department of Defense Survey of Health Related Behaviors Among Active Duty Military Personnel [20]. Participants were asked to indicate the number of drinking occasions during the past month with the question, "During the past 30 days, on how many days did you drink alcohol?". Participants had to identify the quantity of drinks per typical drinking occasion in the table, where columns presented the type of beverage classified as the number of beers (bottle or can $=330 \mathrm{~mL}$ ), the number of wines (glass $=125 \mathrm{~mL}$ ), or the quantity of whiskey/vodka $(\mathrm{mL})$, liquor $(\mathrm{mL})$, and other drinks $(\mathrm{mL})$ by indicating the quantity or amount of each of the drinks in the columns. The number of occasions per month when $\geq 5$ drinks were consumed was determined with the question, "During the past 30 days, on how many days did you have 5 or more drinks of beer, wine, or liquor on the same occasion?" (By "drink," we mean a bottle or can of beer, a wine cooler or a glass of wine, a shot of liquor, or a mixed drink or cocktail. By "occasion," we mean at the same time or within a couple of hours of each other.) Following the 2008 Department of Defense Survey of Health-Related Behaviors Among Active Duty Military Personnel [20] paper, participants were allocated into three groups according to alcohol consumption: abstinent $(0$ alcoholic drinks in the past month), light-moderate drinker (1-4 drinks per typical drinking occasion or $\geq 5$ drinks per typical drinking occasion 1-3 times/month), heavy drinker ( $\geq 5$ drinks per typical drinking occasion $\geq 1$ /week (on average) in the 30 days before the survey). The classification was adapted from Mulford and Miller (1960) [28].

To provide a continuous variable indicating the total amount of alcohol consumed, the total number of alcohol units per month was calculated as one standard unit equal to $10 \mathrm{~g}$ ethanol. In accordance with the $\mathrm{WHO}$ guidelines, the following formula was used: volume $(\mathrm{mL})$ multiplied by the percentage of alcohol and divided by 1000 [29].

\subsubsection{Cigarette Smoking}

Cigarette smoking was evaluated as indicated in the 2008 US Department of Defense Survey of Health Related Behaviors Among Active Duty Military Personnel [20]. Participants were asked to indicate the number of cigarettes smoked in the past month. Given that there is no safe amount of tobacco use, as reported by the 2014 Surgeon General's Report [30], two categories of smoking were created: current nonsmoker (smoked 0 cigarettes in the past 30 days and never smokers) and current smoker (smoked $\geq 1$ cigarette in the past 30 days).

\subsubsection{Psychological Distress}

Psychological distress was assessed using the six-item Kessler scale [31]. Participants were asked to evaluate their nervousness, hopelessness, anxiety, restlessness or fidgety feelings, worthlessness, 
and depression. Each item was scored from 0 (none of the time) to 4 (all the time). The total score was calculated by summing the scores for each item and ranged from 0 to 24 points, with a lower score indicating a lower level of psychological distress. The internal consistency of the scale was good (Cronbach $\alpha=0.876)$. The summed score was dichotomized as low psychological distress ( $0-12$ points) and high psychological distress ( $\geq 13$ points) [31].

\subsection{Covariates}

Body mass index (BMI) was evaluated using the self-reported height and weight and was calculated as weight $(\mathrm{kg}) /$ height $\left(\mathrm{m}^{2}\right)$. Family income was evaluated by asking participants to rate their current family financial situation as having insufficient income, having average income, having higher than average income, wealthy, and rich. Age (in years) was also used as a covariate.

\subsection{Statistical Analysis}

The data were analyzed using SPSS (ver. 24, IBM SPSS Statistics; IBM Corp., Armonk, NY, USA). Categorical variables are presented as frequencies and percentages. Differences in categorical variables were tested using the chi-squared test. The relationships between independent continuous variables were examined using Pearson correlational analysis because all scaled variables had a normal distribution. Logistic regression analysis was used to identify significant associations between dependent (enlistment into MS) and independent variables (covariates, health behaviors, and psychological distress level) by adding independent variables individually into the next model and producing odds ratios (ORs) and 95\% confidence intervals (95\% CIs). The final model contained adjusted OR $(95 \% \mathrm{CI})$. Statistical significance was set at $p<0.05$.

\section{Results}

Among 1243 conscripts who went through the enlistment procedures, 624 (50.2\%) were rejected for and $619(49.8 \%)$ were enlisted into MS (Table 1). Around half were adequately physically active. Among youth enlisted to MS, there were $63.1 \%$ of physically active versus $47.3 \%$ of physically active among youth rejected for MS $(\mathrm{p}<0.01)$. The level of adherence to the Mediterranean diet was low among half of Lithuanian male conscripts, a little bit less than half of them had medium adherence, and only a small percentage (3.5\%) of male conscripts complied with healthy eating patterns. However, there were no significant differences between rejected and enlisted youth $(p>0.05)$. Almost a quarter of all conscripts reported their alcohol abstinence for the previous 30 days, two-thirds reported a light-moderate drinking pattern, and almost one out of ten $(9.6 \%)$ reported heavy drinking. The percentage distribution after Bonferroni correction indicated that among youth enlisted to MS, there were $6.8 \%$ of heavy drinkers versus $12.3 \%$ of heavy drinkers among rejected youth $(p<0.01)$. Percentages of light-moderate drinking and abstinence for the 30 previous days were not significantly different $(p>0.05)$ between rejected and enlisted youth. Almost two-thirds of male conscripts were current smokers; however, smoking was more frequent among those who were rejected for MS (67.7\%) than among those who were enlisted $(57.0 \%)(p<0.0001)$. A high level of distress was reported in $9.1 \%$ of the total population of male conscripts. However, among rejected youth, high distress had $14.7 \%$ of prevalence versus $3.4 \%$ of high distress prevalence among enlisted youth $(p<0.0001)$. 
Table 1. Descriptive statistics and comparison (chi-squared test) between recruits rejected for and enlisted into military service.

\begin{tabular}{|c|c|c|c|c|}
\hline & $\begin{array}{c}\text { Total } \\
(\%)\end{array}$ & $\begin{array}{c}\text { Rejected for } \\
\text { Military Service } \\
\text { (\%) }\end{array}$ & $\begin{array}{c}\text { Enlisted Into } \\
\text { Military Service } \\
(\%)\end{array}$ & $\chi^{2} ; \mathrm{df} ; p$ \\
\hline MVPA & $N=1219$ & & & $31.0 ; 1 ;<0.0001$ \\
\hline Low $(<2.5 \mathrm{~h} /$ week $)$ & 44.7 & 52.6 & 36.9 & \\
\hline Adequate ( $\geq 2.5 \mathrm{~h} /$ week) & 55.3 & 47.4 & 63.1 & \\
\hline Mediterranean diet & $N=630$ & & & $2.3 ; 2 ; 0.315$ \\
\hline Low adherence & 50.2 & 51.5 & 49.4 & \\
\hline Medium adherence & 46.3 & 44.9 & 48.0 & \\
\hline High adherence & 3.5 & 3.6 & 2.6 & \\
\hline Alcohol consumption & $N=1082$ & & & $9.2 ; 2 ; 0.010$ \\
\hline Abstinent ( $\geq 30$ days) & 24.2 & 23.4 & 25.0 & \\
\hline Light-moderate drinker & 66.2 & 64.3 & 68.1 & \\
\hline Heavy drinker & 9.6 & 12.3 & 6.8 * & \\
\hline Cigarette smoking & $N=1179$ & & & $16.1 ; 1 ;<0.0001$ \\
\hline Current nonsmoker & 37.7 & 32.3 & 43.0 & \\
\hline Current smoker & 62.3 & 67.7 & 57.0 & \\
\hline Psychological distress & $N=1159$ & & & $44.4 ; 1 ;<0.0001$ \\
\hline Low & 90.9 & 85.3 & 96.6 & \\
\hline High & 9.1 & 14.7 & 3.4 & \\
\hline
\end{tabular}

Note: Boldface indicates significant values $(p<0.05) ;{ }^{*}$ adjusted $p$ values for $2 \times 3$ comparisons using the Bonferroni method. df, degrees of freedom; MVPA, moderate to vigorous physical activity.

Continuous variables for health behaviors and distress were included in the correlational analysis to examine the relationships between the main predictors of enlistment, and separate analyses were performed for the rejected and enlisted conscripts (Table 2). In both groups, there were significant relationships between better adherence to healthy eating patterns and lower smoking levels $(\mathrm{r}=-0.011$ and $\mathrm{r}=-018$ for rejected and enlisted, respectively) and lower psychological distress levels $(\mathrm{r}=-0.12$ and $r=-0.22$ for rejected and enlisted, respectively). Smoking and distress were also significantly correlated ( $\mathrm{r}=0.12$ in both groups), which showed that a higher psychological distress level was associated with a higher average number of cigarettes smoked per day. In both groups, higher alcohol consumption was related to higher smoking levels $(r=0.22$ and $r=0.24$ for rejected and enlisted, respectively) and higher distress levels ( $r=0.21$ and $r=0.27$ for rejected and enlisted, respectively). Among the men enlisted into MS, there were also significant associations between greater alcohol consumption and lower adherence to healthy eating $(\mathrm{r}=-0.12)$, and between higher compliance to healthy eating patterns and a higher physical activity level $(\mathrm{r}=0.13)\left(p_{\mathrm{s}}<0.05\right)$.

Table 2. Correlations between the predictors of enlistment for recruits rejected for (above the diagonal) and enlisted into (below the diagonal) military service.

\begin{tabular}{|c|c|c|c|c|c|}
\hline & $\begin{array}{c}\text { MVPA } \\
\text { (h/Week) }\end{array}$ & $\begin{array}{c}\text { Mediterranean } \\
\text { Diet }\end{array}$ & $\begin{array}{c}\text { Alcohol } \\
\text { (Units/Month) }\end{array}$ & $\begin{array}{c}\text { Cigarettes } \\
\text { (Number/Day) }\end{array}$ & $\begin{array}{c}\text { Psychological } \\
\text { Distress }\end{array}$ \\
\hline MVPA (h/week) & - & -0.02 & 0.01 & 0.05 & -0.07 \\
\hline Mediterranean diet & 0.13 & - & -0.06 & -0.11 & -0.12 \\
\hline Alcohol (units/month) & -0.03 & -0.12 & - & 0.22 & 0.21 \\
\hline Cigarettes (number/day) & -0.01 & -0.18 & 0.24 & - & 0.12 \\
\hline Psychological distress & -0.07 & -0.22 & 0.27 & 0.12 & - \\
\hline
\end{tabular}

Note: Boldface indicates significant values $(p<0.05)$. MVPA, moderate to vigorous physical activity.

Enlistment into MS was predicted using multiple logistic regression analysis (Table 3). When entered individually into the model, enlistment into military service was associated with MVPA $(\mathrm{OR}=1.97$; CI 1.57-2.47), adversely associated with heavy drinking ( $\mathrm{OR}=0.60$; $\mathrm{CI} 0.45-0.79)$, current smoking $(\mathrm{OR}=0.61 ; \mathrm{CI} 0.49-0.78)$, and psychological distress ( $\mathrm{OR}=0.20 ; \mathrm{CI} 0.13-0.33)$. After controlling 
for all variables included in the regression analysis in Model 7, the significant predictors of enlistment remained higher MVPA, current non-smoking, and low level of distress. Adherence to healthy eating was not significantly related to enlistment neither entered individually nor after controlling for covariates and other study variables $(p>0.05)$. Among the covariates, only older age predicted a lower chance of being enlisted (OR $=0.77 ; 95 \% \mathrm{CI} 0.71-0.83)$. Neither BMI nor perceived family income was associated with enlistment $(p>0.05)$.

Table 3. Multiple logistic regression predicting enlistment to military service from health behaviors and distress in Lithuanian male youth, controlling for family income, body mass index, and age (crude and adjusted odds ratios (ORs)).

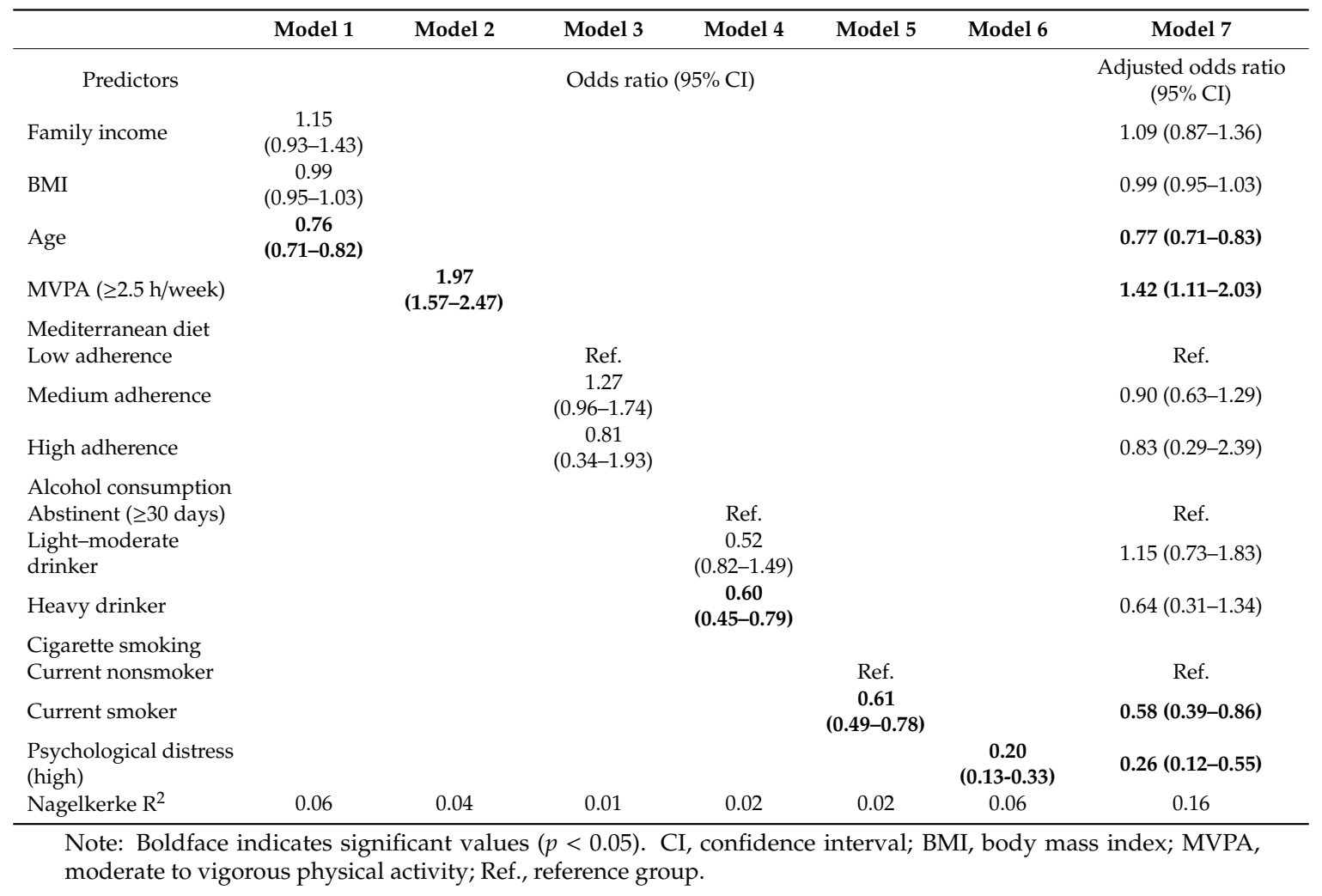

\section{Discussion}

This study was aimed at determining the prevalence of healthy behaviors and psychological distress in recruits for MS and at identifying differences in these indicators between young men rejected for and enlisted into MS. The results partly support the premise that young men who are enlisted into MS are more likely to adhere to healthy behaviors and have lower psychological distress levels compared with those rejected for MS.

\subsection{Physical Activity}

In the regression analysis, after controlling for covariates and other study variables, meeting the recommendations for MVPA was significantly associated with being enlisted into MS. Previous studies have shown that physical activity can help prevent 26 different chronic diseases [17] and is related to a lower incidence of metabolic syndrome, lower rates of stress, and better mental health and cognitive functions $[17,32,33]$, all of which are important to being able to serve in the military. Physical activity is also a strong predictor of physical fitness [34], which is a key indicator of physical health during MS. Other research has suggested that physical activity dampens the inflammatory processes in the body [34]. Higher-intensity physical activity confers greater health benefits, such as reduced body fat and central adiposity, and higher cardiovascular fitness in youth, compared with 
lower-intensity activity [35]. In the current study, 55.3\% of all conscripts had an adequate level of MVPA, but this percentage was lower in those rejected for MS (47.4\%) than in those enlisted (63.1\%) into MS. These results are similar to data reported in the general population of similar age in the Eurobarometer (2017) data, which showed that $55 \%$ of male youth in Lithuania and $57 \%$ of male youth from other European countries aged 15-24 years engage in physical activity regularly or with some regularity [36]. The physical activity level generally increases in those enlisted into MS after they start their duty because MS enforces its own standards for health behaviors such as physical activity by, for example, requiring daily physical activities. Surprisingly, however, it has been reported that $13 \%$ of those serving in the US active duty military perform insufficient exercise [37].

\subsection{Cigarette Smoking}

Along with physical activity, current smoking also predicted enlistment into MS. The logistic regression analysis after controlling for covariates and other study variables indicated that current smokers had a $72 \%$ lower chance of being enlisted than nonsmokers. In total, around two-thirds of Lithuanian male youth called to serve in the military are current smokers. However, among those enlisted to the military, there are $10.7 \%$ less of them than among those rejected for MS. A study in Taiwan reported that $50.8 \%$ of young men in their MS smoked before service [38]; this percentage is 10 percentage points lower than in Lithuania. In the US, $23 \%$ of active duty personnel smoke [36], which is much lower than the $57 \%$ smoking rate in Lithuanian conscripts enlisted into MS in our study. The statistics for the general Lithuanian population confirm the high prevalence of smoking: one in three men smoke every day in Lithuania. This is the fourth highest rate in the European Union [39]. Smoking is related to obesity [40] and hypertension [41], and is the most relevant risk factor for the burden of disease and mortality [39,42]. A low physical activity level and smoking are the most prevalent health risk factors [43] and were also negative predictors of enlistment for MS in our study.

\subsection{Psychological Distress}

Psychological distress was another significant predictor of enlistment into MS in this study. We found by $11 \%$ higher prevalence of high psychological distress among those rejected for than among those enlisted into MS. This effect was independent of health-related behaviors such as physical activity, nutrition, cigarette smoking, and alcohol consumption, which might be interrelated to psychological distress given that these behaviors can act as coping strategies $[7,44,45]$. However, in total, only $9.1 \%$ of these male conscripts reported a high psychological distress level. Another study of the Lithuanian high school male student population, from which the military draws its enlistees, reported a $12.5 \%$ prevalence of psychological distress measured using the same Kessler scale [7]. A study in Massachusetts in the USA found that $20 \%$ of high school students of both sexes reported depressive symptoms [46]. An Australian study of university students reported a prevalence of high psychological distress of $11.1 \%-22.5 \%$ [44]. A prevalence of high psychological distress of $11 \%-18 \%$ was reported for active duty personnel in the US military, and the prevalence was higher among heavy drinkers than among those who consumed less alcohol [20]. This finding suggests an interdependence of heavy alcohol consumption and psychological distress. This association was identified in the correlational analysis in our study; in particular, of the associations of psychological distress with other health behaviors, the association with alcohol consumption was the strongest.

\subsection{Alcohol Consumption and Nutrition}

Alcohol was consumed by $75.8 \%$ of the included youth, and $9.6 \%$ were heavy drinkers. These figures are similar to the heavy or risky drinking behavior noted in about $12 \%$ of Swiss conscripts [19] and $7.8 \%$ of US active duty personnel [36]. In a report on healthy lifestyle factors among adult Lithuanians, the Lithuanian Department of Statistics reported that $34 \%$ of the population consumes alcoholic beverages at least once a month [47]. 
The adherence rates for healthy nutrition among potential conscripts in our study are problematic because only $3.5 \%$ fully complied and $46.3 \%$ partly complied with the healthy eating recommendations. The Country Health Profiles (2019) reported that $32 \%$ of deaths in Lithuania could be attributed to dietary risk factors, a rate that is higher than the $18 \%$ in other European countries. Dietary risk has the highest risk for mortality among other health behaviors: smoking is related to $15 \%$ and $17 \%$, alcohol consumption to $10 \%$ and $6 \%$, and physical inactivity to $5 \%$ and $3 \%$ of deaths in Lithuania and Europe, respectively [39].

The regression analysis did not find any associations between enlistment and alcohol consumption or dietary habits in the final model after controlling for all study variables included, although the differences in the percentages were shown significant for alcohol consumption. Significantly more of the recruits rejected for MS (12.3\%) were heavy drinkers than those enlisted (6.8\%). When entered individually into logistic regression, heavy drinking lowered the chances of being enlisted into MS. However, after the addition of covariates and other study variables, this relationship lost its significance. Moreover, study participants are young men and their history of alcohol consumption may be too short to have a noticeable direct effect on their health. This could also be said about their dietary habits. However, other research has shown that both alcohol use and nutrition over the long term are associated with health outcomes such as the risk of diabetes, cardiovascular disease, Parkinson's disease, certain types of cancer, myocardial infarction, and high blood cholesterol level [48-51].

Overall, our results correspond with those of other studies where health-related behaviors and psychological distress are linked to physical comorbidities [52], which were the main reasons for rejection from MS. Public health policies are targeted at strengthening health in the total population and its subpopulations, such as young people. Similarly, state authorities are also interested in having physically fit and healthy conscripts, who are mostly young men. Improving health among youth is most effective when started early in life during behavior development and when behavioral changes are easier to implement. Health education in an organized way that targets the young population may be best implemented at school, which provides the best setting for delivering public health interventions at a young age. In particular, physical development of school children could be based on physical literacy that addresses attributes, characteristics, skills, and behaviors that are related to the ability for, and commitment to, a healthy, active lifestyle [53]. From the military perspective, these interventions could also be modeled to capture physical capacity (e.g., physical endurance) and psychological resilience (e.g., resistance to stress) and to emphasize the importance of avoiding substance use or abuse. The development of a healthy future military could start at a young age and involve the objectives of both public health and state defense. To implement this, governmental policies and strategies are required to enable intersectional collaboration and shared responsibility among the education, military and health sectors as well as to set up coordinating mechanisms among sectors. Funding and financial incentives should be provided for intervention programs and implementers. National regulations are needed to enable school administrative and staff to expand their competencies and skills in physical and mental health promotion on a basis of compulsory professional training.

\subsection{Study Limitations}

The study has some limitations. We used a cross-sectional design, and no causal inferences can be drawn. It remains unclear whether the poor health behaviors were the causes or the consequences of the health outcomes, which were the reasons for rejection from MS. Longitudinal studies are needed to evaluate the direction of, and interactions between, the associations demonstrated here. Another limitation is that we did not include objective measures of physical and mental health. Physical and/or mental health may be confounding variables that both prevent conscripts from serving in the military and increase the likelihood of exhibiting unhealthy behaviors and having a high psychological distress level. Another possible confounding factor may be the interaction between psychological distress and health behaviors because the latter can result from the former. However, the logistic regression analysis allowed us to control for this possible confounding effect. That is, the health behaviors that were 
significant for enlistment remained significant even after psychological distress levels were included in Model 7. Another limitation is that we did not measure the onset of health-damaging behavior, which may have served as a control variable when examining the predictors of enlistment, especially for addictive behaviors such as smoking and alcohol consumption. In addition, we did not assess the use of other substances such as "party drugs," and we did not obtain a full picture of these conscripts' use patterns.

Our study also has some strengths. This was a nationally representative sample that provides a picture of the health behaviors and prevalence of psychological distress among young men called to serve in the military and the differences between those who were enlisted and rejected for MS. Further research should investigate the relationships between health behaviors in conscripts and the reasons they are rejected.

\section{Conclusions}

Health behaviors in male conscripts are unsatisfactory because about half are physically inactive, have a poor diet, or smoke, and almost one out of 10 is a heavy drinker and has a high psychological distress level. The latter is a concern because of its association with adverse health behaviors. The enlisted conscripts were more likely to be sufficiently physically active and less likely to be current smokers or have a high psychological distress level. Early intervention programs to provide a heathier population of young men for conscription should focus on mental well-being and target health-related behaviors such as physical activity and smoking. Preferably, these should be implemented as health education programs in schools to help prevent the development of adverse health behaviors among young men. Governmental policies and strategies are required to enable intersectional collaboration and shared responsibility among the education, military and health sectors.

Author Contributions: Conceptualization, B.M. and A.E.; Methodology, B.M., V.J.C., and D.V.; Formal Analysis, B.M. and A.E.; Investigation, D.V., V.J.C., and R.Z.-S.; Resources, A.E.; Data Curation, D.V., V.J.C., and R.Z.-S.; Writing-Original Draft Preparation, B.M.; Writing_Review \& Editing, A.E.; Supervision, B.M. All authors have read and agreed to the published version of the manuscript.

Funding: The study was supported by the Lithuanian Research Council.

Acknowledgments: The authors thank the Lithuanian Ministry of Defense and all centers for military recruitment for administrative support.

Conflicts of Interest: The authors declare no conflict of interest. The sponsors had no role in the study design, execution, interpretation, or writing of the study.

\section{References}

1. Aubert, S.; Barnes, J.D.; Abdeta, C.; Nader, P.A.; Adeniyi, A.F.; Aguilar-Farias, N.; Andrade Tenesaca, D.S.; Bhawra, J.; Brazo-Sayavera, J.; Cardon, G. Global matrix 3.0 physical activity report card grades for children and youth: Results and analysis from 49 countries. J. Phys. Act. Health 2018, 15, S251-S273. [CrossRef] [PubMed]

2. López-Sánchez, G.; Emeljanovas, A.; Miežienè, B.; Díaz-Suárez, A.; Sánchez-Castillo, S.; Yang, L.; Roberts, J.; Smith, L. Levels of physical activity in Lithuanian adolescents. Medicina 2018, 54, 84. [CrossRef]

3. Venckunas, T.; Emeljanovas, A.; Mieziene, B.; Volbekiene, V. Secular trends in physical fitness and body size in Lithuanian children and adolescents between 1992 and 2012. J. Epidemiol. Community Health 2016, 71, 181-187. [CrossRef] [PubMed]

4. Mieziene, B.; Emeljanovas, A.; Novak, D.; Kawachi, I. The Relationship between Social Capital within Its Different Contexts and Adherence to a Mediterranean Diet Among Lithuanian Adolescents. Nutrients 2019, 11, 1332. [CrossRef]

5. Novak, D.; Štefan, L.; Prosoli, R.; Emeljanovas, A.; Mieziene, B.; Milanović, I.; Radisavljević-Janić, S. Mediterranean diet and its correlates among adolescents in non-Mediterranean European countries: A population-based study. Nutrients 2017, 9, 177. [CrossRef] 
6. Göbel, K.; Scheithauer, H.; Bräker, A.B.; Jonkman, H.; Soellner, R. Substance use patterns among adolescents in Europe: A latent class analysis. Subst. Use Misuse 2016, 51, 1130-1138. [CrossRef]

7. Novak, D.; Popović, S.; Emeljanovas, A.; Mieziene, B.; Krističević, T. Are family, neighbourhood and school social capital associated with psychological distress among lithuanian high-school students? A cross-sectional study. IJSMaRT 2016, 1, 75-89.

8. Darlington, G.A.; Kreiger, N.; Lightfoot, N.; Purdham, J.; Sass-Kortsak, A. Prostate cancer risk and diet, recreational physical activity and cigarette smoking. Chronic Dis. Can. 2007, 27, 145-153.

9. Koene, R.J.; Prizment, A.E.; Blaes, A.; Konety, S.H. Shared risk factors in cardiovascular disease and cancer. Circulation 2016, 133, 1104-1114. [CrossRef]

10. Hammen, C. Risk factors for depression: An autobiographical review. Annu Rev. Clin Psychol. 2018, 14, 1-28. [CrossRef]

11. Stubbs, B.; Vancampfort, D.; Firth, J.; Schuch, F.B.; Hallgren, M.; Smith, L.; Koyanagi, A. Relationship between sedentary behavior and depression: A mediation analysis of influential factors across the lifespan among 42,469 people in low-and middle-income countries. J. Affect. Disord. 2018, 229, 231-238. [CrossRef] [PubMed]

12. Vancampfort, D.; Stubbs, B.; Herring, M.P.; Hallgren, M.; Koyanagi, A. Sedentary behavior and anxiety: Association and influential factors among 42,469 community-dwelling adults in six low-and middle-income countries. Gen. Hosp. Psychiatry 2018, 50, 26-32. [CrossRef] [PubMed]

13. Ding, D.; Lawson, K.D.; Kolbe-Alexander, T.L.; Finkelstein, E.A.; Katzmarzyk, P.T.; van Mechelen, W.; Pratt, M. Lancet Physical Activity Series 2 Executive Committee. The economic burden of physical inactivity: A global analysis of major non-communicable diseases. Lancet 2016, 388, 1311-1324. [CrossRef]

14. Šaukiamuju I Privalomają Pradinę Karo Tarnyba Jaunuolių Ir Šią Tarnybą Atliekančiu Karių Sveikata: Itaką Darantys Veiksniai Ir Sveikatą Gerinančios Priemonès (Health of Conscripts And Enlisted yo The Military Service: Influencing Factors And Means For Health Improvement). Available online: https: //www.lmt.1t/lt/doclib/cwpnkccecvdnbe5erz9v8tsuqrahwk4 (accessed on 20 July 2019).

15. Mahmoud, R.A.; Clark, K.L.; May, L.A. Evolution of Military Recruit Accession Standards. Mil. Prev. Med. Mobil. Deploy. 2003, 1, 145-158.

16. Asch, B.J.; Buck, C.; Klerman, J.A.; Kleykamp, M.; Loughran, D.S. Military Enlistment Of Hispanic Youth: Obstacles and Opportunities; MG-773-OSD; RAND Corporation: Santa Monica, CA, USA, 2009. Available online: https://www.rand.org/pubs/monographs/MG773.htm (accessed on 2 September 2019).

17. Pedersen, B.K.; Saltin, B. Exercise as medicine-evidence for prescribing exercise as therapy in 26 different chronic diseases. Scand. J. Med. Sci. Sports 2015, 25, 1-72. [CrossRef]

18. Puterman, E.; Lin, J.; Krauss, J.; Blackburn, E.H.; Epel, E.S. Determinants of telomere attrition over 1 year in healthy older women: Stress and health behaviors matter. Mol. Psychiatry 2015, 20, 529. [CrossRef]

19. Dey, M.; Gmel, G.; Studer, J.; Mohler-Kuo, M. Health-risk behaviors and quality of life among young men. Qual. Life Res. 2014, 23, 1009-1017. [CrossRef]

20. Bray, R.M.; Pemberton, M.R.; Hourani, L.L.; Witt, M.; Olmsted, K.L.; Brown, J.M.; Scheffler, S. Department of Defense Survey of Health Related Behaviors among Active Duty Military Personnel; Research Triangle Inst (Rti) Research Triangle Park Nc: Durham, NC, USA, 2009.

21. Bray, R.M.; Hourani, L.L.; Rae Olmsted, K.L.; Witt, M.; Brown, J.M.; Pemberton, M.R.; Vandermaas-Peeler, R. Department of Defense Survey of Health Related Behaviors among Active Duty Military Personnel. Research Triangle Inst (Rti) Research Triangle Park Nc: Durham, NC, USA, 2006.

22. Mikkola, I.; Jokelainen, J.J.; Timonen, M.J.; Ärkönen, P.K.; Saastamoinen, E.; Laakso, M.A.; Mäkinen, T.M. Physical activity and body composition changes during military service. Med. Sci. Sports Exerc. 2009, 41, 1735-1742. [CrossRef]

23. Lietuvos Respublikos krašto apsaugos ministro ir Lietuvos Respublikos sveikatos apsaugos ministro ısakymas Dèl sveikatos būklès ıvertinimo principu, metodikos ir tinkamumo karo ar civilinei krašto apsaugos tarnybai pagal sveikatos būklę kriteriju patvirtinimo [The Order on the Approval Principles, Methodology and Approval Criteria for Health for War and Civilian Defense]. Available online: https: //www.e-tar.lt/portal/en/legalAct/TAR.D17DE0C6B37F (accessed on 2 January 2020).

24. World Health Organization. Global Strategy on Diet, Physical Activity and Health. Available online: https://www.who.int/dietphysicalactivity/physical_activity_intensity/en/ (accessed on 4 January 2020). 
25. World Health Organization. Global Action Plan on Physical Activity 2018-2030: More Active People for a Healthier World; World Health Organization: Geneva, Switzerland, 2018. Available online: https:/apps.who.int/iris/ bitstream/handle/10665/272722/9789241514187-eng.pdf?ua=1 (accessed on 31 August 2019).

26. Martínez-González, M.A.; García-Arellano, A.; Toledo, E.; Salas-Salvado, J.; Salas-Salvadó, J.; Buil-Cosiales, P.; Corella, D. A 14-item Mediterranean diet assessment tool and obesity indexes among high-risk subjects: The PREDIMED trial. PLoS ONE 2012, 7, e43134. [CrossRef]

27. Hebestreit, A.; Intemann, T.; Siani, A.; De Henauw, S.; Eiben, G.; Kourides, Y.; Pigeot, I. Dietary patterns of European children and their parents in association with family food environment: Results from the I. family study. Nutrients 2017, 9, 126. [CrossRef]

28. Mulford, H.A.; Miller, D.A. Drinking in Iowa: 2. The extent of drinking and selected sociocultural categories. Q. J. Stud. Alcohol. 1960, 21, 26-39. [PubMed]

29. Department of Health. Alcohol Units A Brief Guide. 2008. Available online: https://x.iriss.org.uk/sites/ default/files/resources/Alcohol\%20Units\%20a\%20brief\%20guide.pdf (accessed on 31 August 2019).

30. Alberg, A.J.; Shopland, D.R.; Cummings, K.M. The 2014 Surgeon General's report: Commemorating the 50th Anniversary of the 1964 Report of the Advisory Committee to the US Surgeon General and updating the evidence on the health consequences of cigarette smoking. Am. J. Epidemiol. 2014, 179, 403-412. [CrossRef] [PubMed]

31. Kessler, R.C.; Barker, P.R.; Colpe, L.J.; Epstein, J.F.; Gfroerer, J.C.; Hiripi, E.; Zaslavsky, A.M. Screening for serious mental illness in the general population. Arch. Gen. Psychiatry 2003, 60, 184-189. [CrossRef] [PubMed]

32. Hillman, C.H.; Motl, R.W.; Pontifex, M.B.; Posthuma, D.; Stubbe, J.H.; Boomsma, D.I.; de Geus, E.J.C. Physical activity and cognitive function in a cross-section of younger and older community-dwelling individuals. Health Psychol. 2006, 25, 678-687. [CrossRef]

33. Watson, A.; Timperio, A.; Brown, H.; Best, K.; Hesketh, K.D. Effect of classroom-based physical activity interventions on academic and physical activity outcomes: A systematic review and meta-analysis. Int. J. Behav. Nutr. Phys. Act. 2017, 14, 114. [CrossRef]

34. Mikkelsen, K.; Stojanovska, L.; Polenakovic, M.; Bosevski, M.; Apostolopoulos, V. Exercise and mental health. Maturitas 2017, 106, 48-56. [CrossRef]

35. Gralla, M.H.; McDonald, S.M.; Breneman, C.; Beets, M.W.; Moore, J.B. Associations of objectively measured vigorous physical activity with body composition, cardiorespiratory fitness, and cardiometabolic health in youth: A review. Am. J. Lifestyle Med. 2019, 3, 61-97. [CrossRef]

36. European Commission. Special Eurobarometer 472. Sport and Physical Activity; Brussel, Belgium, 2018. Available online: http://eose.org/wp-content/uploads/2018/03/ebs_472_en.pdf (accessed on 2 January 2020).

37. Hoerster, K.D.; Lehavot, K.; Simpson, T.; McFall, M.; Reiber, G.; Nelson, K.M. Health and Health Behavior Differences. Am. J. Prev. Med. 2012, 43, 483-489. [CrossRef]

38. Chu, N.F.; Wu, D.M.; Shen, M.H.; Lin, Y.S. Prevalence of adverse behaviors among young military conscripts in Taiwan. Mil. Med. 2006, 171, 301-305. [CrossRef]

39. Lithuania: Country Health Profile 2019. State of Health in the EU. Available online: http://www.oecd.org/ publications/lithuania-country-health-profile-2019-35913deb-en.htm (accessed on 27 January 2020).

40. Gruber, J.; Frakes, M. Does falling smoking lead to rising obesity? J. Health Econ. 2006, 25, 183-197. [CrossRef]

41. Soriano, J.B.; Rojas-Rueda, D.; Alonso, J.; Antó, J.M.; Cardona, P.-J.; Fernández, E.; Garcia-Basteiro, A.L.; Benavides, F.G.; Glenn, S.D.; Krish, V.; et al. The burden of disease in Spain: Results from the Global Burden of Disease 2016. Med. Clín. (Engl. Ed.) 2018, 151, 171-190. [CrossRef]

42. Kayame, R.; Mallongi, A. Relationships between Smoking Habits and the Hypertension Occurrence among the Adults of Communities in Paniai Regency, Papua Indonesia. Indian J. Public Health Res. Dev. 2018, 9, 332. [CrossRef]

43. World Health Organization. Global Health Risks: Mortality and Burden of Disease Attributable to Selected Major Risks; World Health Organization: Geneva, Switzerland, 2009. Available online: https://apps. who.int/iris/bitstream/handle/10665/44203/9789241563871_eng.pdf?sequence=1\&isAllowed=y (accessed on 1 September 2019).

44. Cvetkovski, S.; Reavley, N.J.; Jorm, A.F. The prevalence and correlates of psychological distress in Australian tertiary students compared to their community peers. Aust. N. Z. J. Psychiatry 2012, 46, 457-467. [CrossRef] 
45. Hagman, B.T.; Delnevo, C.D.; Hrywna, M.; Williams, J.M. Tobacco use among those with serious psychological distress: Results from the national survey of drug use and health, 2002. Addict. Behav. 2008, 33, 582-592. [CrossRef] [PubMed]

46. Schneider, S.K.; O'Donnell, L.; Stueve, A.; Coulter, R.W. Cyberbullying, school bullying, and psychological distress: A regional census of high school students. Am. J. Public Health 2012, 102, 171-177. [CrossRef] [PubMed]

47. Lithuanian Department of Statistics. Results of the Health Interview Survey of the Population of Lithuania. 2014. Available online: https://osp.stat.gov.lt/services-portlet/pub-edition-file? (accessed on 6 January 2020).

48. Alcalay, R.N.; Gu, Y.; Mejia-Santana, H.; Cote, L.; Marder, K.S.; Scarmeas, N. The association between Mediterranean diet adherence and Parkinson's disease. Mov Disord. 2012, 27, 771-774. [CrossRef]

49. Gotsis, E.; Anagnostis, P.; Mariolis, A.; Vlachou, A.; Katsiki, N.; Karagiannis, A. Health benefits of the Mediterranean diet: An update of research over the last 5 years. Angiology 2015, 66, 304-318. [CrossRef]

50. Romelsjö, A.; Allebeck, P.; Andréasson, S.; Leifman, A. Alcohol, mortality and cardiovascular events in a 35 year follow-up of a nationwide representative cohort of 50,000 Swedish conscripts up to age 55. Alcohol Alcohol. 2012, 47, 322-327. [CrossRef]

51. Sofi, F.; Macchi, C.; Abbate, R.; Gensini, G.F.; Casini, A. Mediterranean diet and health. Biofactors 2013, 39, 335-342. [CrossRef]

52. Strine, T.W.; Kobau, R.; Chapman, D.P.; Thurman, D.J.; Price, P.; Balluz, L.S. Psychological distress, comorbidities, and health behaviors among US adults with seizures: Results from the 2002 National Health Interview Survey. Epilepsia 2005, 46, 1133-1139. [CrossRef]

53. Francis, C.E.; Longmuir, P.E.; Boyer, C.; Andersen, L.B.; Barnes, J.D.; Boiarskaia, E.; ... Tremblay, M.S. The Canadian Assessment of Physical Literacy: Development of a Model of Children's Capacity for a Healthy, Active Lifestyle Through a Delphi Process. J. Phys. Act. Health 2016, 13, 214-222. [CrossRef] [PubMed]

(C) 2020 by the authors. Licensee MDPI, Basel, Switzerland. This article is an open access article distributed under the terms and conditions of the Creative Commons Attribution (CC BY) license (http://creativecommons.org/licenses/by/4.0/). 